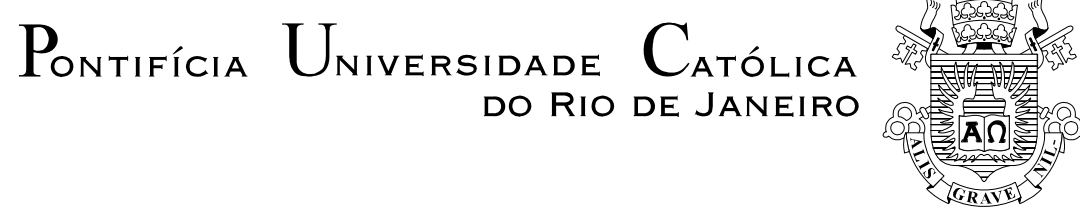

Juliana Porto Fontes

Literatura e ação política: análise de dois romances de Boaventura Cardoso

Dissertação apresentada como requisito parcial para obtenção do grau de Mestre pelo Programa de PósGraduação em Letras do Departamento de Letras do Centro de Teologia e Ciências Humanas da PUC-Rio.

Professor Orientador Alexandre Montaury

Rio de Janeiro

Abril de 2009 


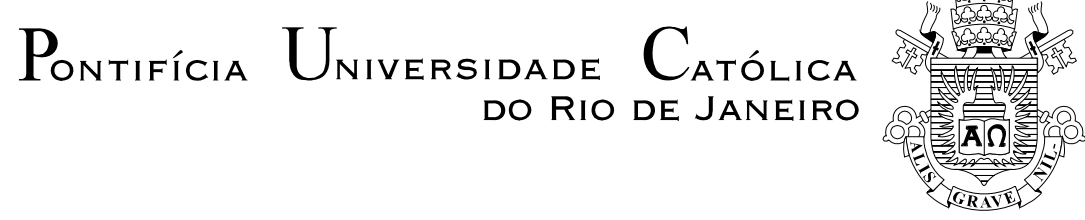

Juliana Porto Fontes

\section{Literatura e ação política: análise de dois romances de Boaventura Cardoso}

Dissertação apresentada como requisito parcial para obtenção do grau de Mestre pelo Programa de Pós-Graduação em Letras do Departamento de Letras do Centro de Teologia e Ciências Humanas da PUC-Rio. Aprovada pela Comissão Examinadora abaixo assinada.

Prof. Alexandre Montaury Baptista Coutinho Orientador Departamento de Letras - PUC-Rio

Profa. Eneida Leal Cunha Departamento de Letras - PUC-Rio

Profa. Izabel Margato Departamento de Letras - PUC-Rio

Prof. Paulo Fernando Carneiro de Andrade

Coordenador Setorial do Centro de Teologia e Ciências Humanas - PUC-Rio

Rio de Janeiro, 6 de abril de 2009. 
Todos os direitos reservados. É proibida a reprodução total ou parcial do trabalho sem autorização do autor, do orientador e da universidade.

\section{Juliana Porto Fontes}

Graduou-se em Letras (Português / Literaturas de Língua Portuguesa) pela Universidade Federal do Rio de Janeiro, em 2005, e especializou-se em Literatura Brasileira - Mediações entre Literatura e Cultura pela Pontifícia Universidade Católica do Rio de Janeiro, em 2007.

Ficha Catalográfica

Fontes, Juliana Porto

Literatura e ação política : análise de dois romances de Boaventura Cardoso / Juliana Porto Fontes ; orientador: Alexandre Montaury Baptista Coutinho. 2009.

$94 \mathrm{f.} ; 30 \mathrm{~cm}$

Dissertação (Mestrado em Letras)-Pontifícia Universidade Católica do Rio de Janeiro, Rio de Janeiro, 2008.

Inclui bibliografia

1. Letras - Teses. 2. Literatura. 3. Política. 4. Sociedade. 5. Identidade. 6. CPLP. I. Coutinho, Alexandre Montaury Baptista. II. Pontifícia Universidade Católica do Rio de Janeiro. Departamento de Letras. III. Título. 
Dedicatória

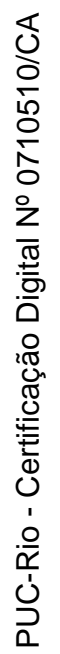

À minha família. 


\section{Agradecimentos}

Aos meus pais, Celso e Nazaré, por sempre acreditarem no meu sucesso.

Ao meu marido, Pedro, pela infinita paciência e pelo indispensável companheirismo.

À minha irmã, Carolina, e meu cunhado, Werther, pelo constante apoio e pela força no inglês.

Aos queridos tios Marcos, Lia e Fred, por sempre incentivarem meus estudos.

A Mel e Téo, por me distraírem tão graciosamente.

Às amigas Jarcélen e Márcia, por serem tão especiais.

Ao meu orientador Alexandre Montaury, por confiar no meu trabalho.

A todos os professores que pude conhecer ao longo da minha vida e que de alguma forma contribuíram para essa conquista.

Ao CNPq e à PUC-Rio, pelos auxílios concedidos para a realização dessa dissertação. 


\section{Resumo}

Fontes, Juliana Porto; Montaury, Alexandre. Literatura e ação política: análise de dois romances de Boaventura Cardoso. Rio de Janeiro, 2009. 94 p. Dissertação de Mestrado - Departamento de Letras, Pontifícia Universidade Católica do Rio de Janeiro.

Esta pesquisa percorre a história da produção literária angolana, buscando situar a obra ficcional de Boaventura Cardoso no contexto das literaturas de expressão portuguesa. A partir desta análise preliminar, pretende-se demonstrar o posicionamento do escritor como intelectual, Ministro da Cultura de Angola, e como ficcionista, tomando os romances Maio, Mês de Maria e Mãe, Materno Mar como produções fundamentais, resultantes das conquistas obtidas ao longo de um século tumultuado como o século XX. Ao examinar a articulação de projetos político-culturais que posicionam Angola num debate crítico acerca da globalização, esta dissertação tem como objetivo principal contribuir com um quadro teórico de questões relativas à cultura, nação e identidade no espaço da lusofonia.

\section{Palavras-chave}

Literatura; política; sociedade; identidade; CPLP 


\section{Abstract}

Fontes, Juliana Porto; Montaury, Alexandre. Literature and political action: an examination of two novels of Boaventura Cardoso. Rio de Janeiro, 2009. 94 p. MSc. dissertation - Departamento de Letras, Pontifícia Universidade Católica do Rio de Janeiro.

This research runs through Angola's history and literary production, aiming to place the fictional work of Boaventura Cardoso within the context of the literatures of portuguese expression. This preliminary analysis seeks to state the writer's position as an intellectual, Angola's Minister Of Culture and fiction writer, by considering the novels Maio, Mês de Maria and Mãe, Materno Mar as core productions which resulted from the conquests achieved through a disturbed 20th century. Through the examination of the political-cultural projects which place Angola in a critical debate regarding globalization, this thesis main objective is contributing to a theoretical framework of questions that relate to culture, nation and identity in the field of lusophony.

\section{Keywords}

Literature; politics; society; identity; CPLP. 


\section{Sumário}

1. Introdução

A literatura em ex-colônias portuguesas 10

2. Da literatura colonial à Literatura Angolana

2.1. Literatura de formação colonial .19

2.2. Afirmar uma Literatura Angolana

2.2.1. Cultura e crítica

2.2.2. Angolanidade 30

2.3. Literatura pós-75 35

3. Boaventura Cardoso no contexto político-histórico angolano .40

4. Os romances de Boaventura Cardoso 47

4.1. Língua, linguagem e tradição .51

4.2. Sociedade e poder 62

4.2.1. A arte de conquistar seguidores, a arte de enfeitiçar multidões. .75

5. Conclusão .83

6. Referências Bibliográficas .86 
Estamos, com efeito, diante de sinais de que, hoje no Brasil, os estudos africanos ganham novos contornos, e, a cada dia, reafirma-se a ligação que setores hegemônicos de nossa sociedade tentaram apagar. Com entusiasmo, percebemos que o país vem se empenhando no resgate de uma memória que permaneceu esmaecida, e isso significa abrir caminhos em direção à África e desvelar as áfricas que existem nas matrizes que nos recortam a identidade. Abrir caminhos que permitam aprofundar o conhecimento parece-nos uma tarefa importante, fundamental para afastar os riscos de se perpetuar o processo de exotização de que o continente também é vítima.

Rita Chaves e Tânia Macedo 